Etnográfica

Revista do Centro em Rede de Investigação em

Antropologia

vol. $18(2) \mid 2014$

Vol. $18(2)$

\title{
Com um pé dentro e outro fora: reflexões pessoais sobre a geração dos eighties
}

Inside and out: personal musings on the eighties' generation

\section{Miguel Vale de Almeida}

\section{(2) OpenEdition}

Journals

Edição electrónica

URL: https://journals.openedition.org/etnografica/3742

DOI: 10.4000/etnografica.3742

ISSN: 2182-2891

\section{Editora}

Centro em Rede de Investigação em Antropologia

\section{Edição impressa}

Data de publição: 1 junho 2014

Paginação: 379-384

ISSN: 0873-6561

\section{Refêrencia eletrónica}

Miguel Vale de Almeida, «Com um pé dentro e outro fora: reflexões pessoais sobre a geração dos eighties», Etnográfica [Online], vol. 18 (2) | 2014, posto online no dia 09 julho 2014, consultado o 10 fevereiro 2022. URL: http://journals.openedition.org/etnografica/3742 ; DOI: https://doi.org/10.4000/ etnografica.3742

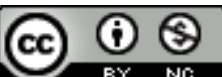

Etnográfica is licensed under a Creative Commons Attribution-NonCommercial 4.0 International License. 


\section{Com um pé dentro e outro fora: reflexões pessoais sobre a geração dos eighties}

\section{Miguel Vale de Almeida}

A partir de uma abordagem subjetiva, identificam-se os principais elementos do "ar do tempo" que contextualizou o aprendizado da antropologia no início da década de 1980 em Portugal, marcada pela "normalização democrática" e por processos de internacionalização visando quer a Europa quer os Estados Unidos.

PALAVRAS-CHAVE: revolução, democracia, Europa, Estados Unidos, internacionalização, experimentação.

Inside and out: personal musings on the eighties' generation - This personal piece aims at identifying the main aspects of the 'Zeitgeist' in Portugal in the 1980s and how it affected the coming of age of an Anthropology student, namely the post-revolutionary 'democratic normalization' and the processes of internationalization (with European and US influences).

KEYWORDS: revolution, democracy, Europe, USA, internationalization, experimentation.

ALMEIDA, Miguel Vale de (miguelva@gmail.com) - Centro em Rede de Investigação em Antropologia (CRIA), ISCTE - Instituto Universitário de Lisboa (ISCTE -IUL), Portugal. 
TERMINEI A LICENCIATURA EM ANTROPOLOGIA EM 1983 NA FACULDADE de Ciências Sociais e Humanas da Universidade Nova de Lisboa. Fi-lo com pouco mais de uma dúzia de outros colegas. No ano "acima" do nosso a turma era muitíssimo mais reduzida. E no ano "acima" desse creio que eram três ou quatro pessoas. Tratava-se do ressurgimento da antropologia no período pós-25 de Abril, no contexto de uma Universidade também ela nova.

As pessoas da minha idade tinham assistido ao 25 de Abril com mais ou menos 13 anos. Tinham vivido o período revolucionário em plena adolescência, em muitos casos bebendo todo o clima de contestação e de reinvenção do mundo. Tinham também assistido à normalização democrática e esperavam a adesão do país à CEE. Filhos e filhas, na sua maioria, das classes médias da capital, muitos e muitas de nós tínhamos feito uma tripla rutura: naturalmente com o Portugal pré-25 de Abril; com os excessos e utopias do período revolucionário; e com o que se anunciava como uma mediania prometida pela normalização democrática. Na idade da universidade, que é a idade de todas as consolidações de visão do mundo, para muitos de nós tratava-se de procurar uma alternativa. E o que se afigurava como alternativa era uma visão, à falta de melhor palavra, cosmopolita, urbana, experimental, diferenciadora, questionadora de dogmas à direita e à esquerda. Ainda não estávamos expostos à verdadeira globalização, a da Internet, mas estávamos claramente atentos às circulações de mercadorias e símbolos da cultura popular. Recusávamos simultaneamente as visões alternativas dos designados "anos 60", marcadas por preocupações antiditatoriais e por utopias ideológicas que muitas vezes remetiam para visões românticas de enobrecimento do "popular", e recusávamos as visões dos “anos 70" que denotavam o investimento de energia e a frustração do período revolucionário. Muito rapidamente fomos experimentando: experimentando a noite e o surgimento da movida do Bairro Alto, experimentando as viagens cada vez mais facilitadas, experimentando as tendências artísticas marcadas pelo lúdico, experimentando as limitações impostas pelo surgimento do VIH-sida, experimentando novas áreas de conhecimento que apontassem no sentido da pluralidade, da diferença, da tolerância, da descoberta da alteridade, de um entrosamento entre ciência, transformação e criação. Talvez daí a sedução que a antropologia exerceu sobre nós.

É certo que, no decurso da aprendizagem antropológica, nos confrontámos com os equivalentes disciplinares dessas referências com que lidávamos e negociávamos. Percebemos a herança colonial da antropologia e isso perturbou-nos. Percebemos o valor, mas também as limitações em termos de afinidades eletivas, da antropologia do rural e do popular português. Percebemos o potencial, mas também o positivismo implícito, da herança do estruturalismo. E percebemos o potencial do que ia chegando, mais hesitantemente, dos contextos anglófonos. Fizemos o nosso bricolage com tudo isto, e esse bricolage era o resultado do caráter eclético, no bom e no mau sentido, do ensino que tivemos, com 
docentes vindos de todas estas tradições, alguns tentando inovar e tentando novas sínteses, e fizemo-lo num ambiente de fragilidade académica, material, de dificuldade de acesso aos textos incomparável com as condições atuais.

Constituímo-nos, pois, como a geração dos anos 80. Quais as principais características?

1. O 25 de Abril, a normalização e a Europa. Creio que este dado é inquestionável. Somos, as pessoas da minha idade, a geração do 25 de Abril, a primeira a frequentar a universidade em ambiente de liberdade intelectual e académica, e isso conferiu-nos uma ideia de liberdade de pensamento que, creio, é distinta quer da "ânsia" de liberdade da geração anterior, quer da aceitação da adequação às "encomendas" que pode caracterizar alguma da ciência "normal" feita por gerações subsequentes. Viríamos também a ser a primeira geração a quebrar com as linhagens antropológicas sediadas nos grandes centros - EUA, Reino Unido, França - e a participar na construção de um ambiente antropológico europeu. Assistimos à fundação da EASA (European Association of Social Anthropologists) em Coimbra e muitos de nós entraram nessa rede como rede privilegiada, feita de pluralidades e hibridismos teóricos e temáticos.

2. Os anos 80 assistiram ao primeiro surto de cosmopolitismo, sobretudo em Lisboa. A conexão entre "aprender e fazer antropologia", por um lado, e as atividades e consumos artísticos, por outro, não deve ser descurada. Um antigo binómio, o que opunha cultura erudita a cultura popular (no sentido da ruralidade e da tradição) deixou de fazer sentido absoluto e um terceiro fator, a cultura popular (no sentido contemporâneo do termo), para mais permeada pelas atividades artísticas e de cultura de massas, impôs-se. Isto foi amparado por transformações na antropologia internacional, às quais fomos sendo cada vez mais sensíveis, quanto mais os meios de comunicação e as viagens o foram permitindo: a importância da História, da economia política, da ideia de construção social, do processualismo, da definição de terrenos não ancorados em geografias ou etnicidades específicas, a preocupação com a escrita ou o documentário audiovisual, a interdisciplinaridade, etc.

3. Muitos de nós fizeram também uma rutura com tradições académicas anteriores a favor de uma abertura à influência anglo-americana. Tal deve-se a razões sociológicas específicas, como a aposta na aprendizagem do inglês pelos filhos por parte da classe média portuguesa, o processo de globalização como um processo de anglofonização do mundo, a quebra da influência cultural francesa. Não há que subestimar este fator, pois a aceitação da influência anglo-americana significava não só abraçar linhas teóricas e temáticas, mas também retóricas e estilos, sensibilidades, para mais reforçadas por uma influência cultural genérica em termos de referências, visões do mundo e valores. 
4. Os últimos pontos, aliás, apontam no sentido da recusa quer das grandes narrativas políticas e ideológicas, quer das grandes narrativas teóricas, das grandes grelhas de interpretação e análise. Processos deste tipo normalmente materializam-se em formas de estar e ser, com os seus códigos culturais que, no nosso caso, passaram pela ideia de democratização da universidade e do conhecimento, da recusa de um certo elitismo e de um certo "mofo" académico. Uma boa etnografia desses tempos talvez o demonstrasse através de coisas tão banais como a roupa, o sexo, a música, o uso da língua oral e escrita, os posicionamentos identitários face a professores, orientadores, chefes, colegas.

5. Mas a geração dos anos 80 tem outra característica. Por razões óbvias ela viria a ocupar os lugares profissionais, académicos, de uma antropologia renovada e em crescimento. Fosse na FCSH, fosse depois no ISCTE ou, depois ainda, nas universidades regionais que foram surgindo com o desenvolvimento pós-adesão à CEE, os lugares de docência foram sendo ocupados por esta geração, completando-se o processo com o recrutamento de jovens licenciados com pouca diferença etária em relação à minha geração e já em parte lecionados por ela. Depois foi o fecho do crescimento, a retração e eventualmente o surgimento das novas formas de trabalho que vieram marcar as gerações subsequentes - na investigação, nas bolsas, na precariedade prolongada. Ocupando praticamente os últimos lugares da instituição universitária, participando portanto das estruturas de poder académico, e ao mesmo tempo fazendo-o com uma visão do mundo substancialmente diferente do elitismo anterior - isto conferiu à minha geração uma responsabilidade peculiar, nem sempre cumprida, mas sobretudo conferiu um privilégio.

6. O que fizemos? Correndo o risco de algum narcisismo, mas sobretudo por não querer falar do trabalho dos outros e, assim, correr o risco de cometer alguma injustiça por omissão, deixem-me tentar usar o meu caso como mero exemplo, recorrendo o mais possível a uma visão distanciada.

Em 1989 publiquei o meu primeiro texto de antropologia (Almeida 1989). Foi num volume de homenagem a Ernesto Veiga de Oliveira, alguém que tive ainda o privilégio de conhecer e que tinha a qualidade extraordinária de se entusiasmar com os meus anseios juvenis. O meu texto era sobre homossexualidade numa visão antropológica. Era o resultado de um trabalho feito nos EUA, numa cadeira de mestrado. Reparem como estes elementos - mestrado nos EUA, trabalho sobre homossexualidade naquela época e um volume de homenagem a Ernesto - condensam um tempo e um modo de transição.

Em 1986, regressado desse mestrado tinha entrado para o corpo docente do ISCTE, como assistente de Raúl Iturra, com quem faria o meu doutoramento sobre género, especificamente sobre construção social da masculinidade (Almeida 1995). Também aqui, notem a composição dos elementos: 
o crescimento do ensino da antropologia, a nova licenciatura do ISCTE feita a partir do retorno de exilados em contextos anglo-saxónicos, a escolha de uma temática praticamente ausente da antropologia portuguesa anterior e conectada com preocupações político-sociais.

O meu trabalho de campo também apontava no sentido de elementos de charneira. Feito em Portugal e em ambiente não urbano, no entanto não buscava um retrato de cultura popular rural, associada tradicionalmente ao Norte do país: não só versava uma localidade alentejana, como a atividade económica principal daquela não era já rural. Mas o trabalho de campo de um ano, com residência continuada, ainda foi possível; se bem que a escolha do meu próprio país tivesse a ver já com a vontade de fazer uma antropologia que não assentasse na especialização étnico-linguística do antropólogo, mas sim no real próximo - o meu país não como busca da tradição, mas o meu país como o banal da vida corrente.

Se a educação norte-americana facilitou e confirmou a viragem para a influência anglófona, isso significou sobretudo, no entanto, a viragem para a pluralidade global. De facto, dois elementos foram importantes na minha carreira doravante: a integração em redes europeias de antropologia e a integração em redes lusófonas de antropologia, nomeadamente com a antropologia brasileira. Acho que foi a minha geração que incentivou e garantiu que isto acontecesse, hoje provavelmente um fenómeno bem mais sólido do que as afinidades eletivas com os três anteriores contextos clássicos, os EUA, o Reino Unido ou a França. O meu segundo terreno, no Brasil, e preocupado ainda com categorias de classificação e discriminação sociais (agora a "raça", como antes o género ou, depois, a orientação sexual) é sintomático do que afirmei acima. Para mais, foi muito forte em anos recentes, entre muitos de nós, a preocupação em lidar, a partir de Portugal, ou a partir da Europa, ou a partir da conexão luso-brasileira, com as influências ou modas que a globalização americocêntrica foi produzindo, dos estudos culturais aos pós-coloniais.

Ao longo de todo este percurso raramente houve ancoramentos a "escolas", a "teorias", a "mestres", num movimento de bricolage e de abertura e de suspensão da crença que creio caracterizar todo o pensamento em ciências sociais dos anos 80 para cá. Por vezes só mesmo a herança - os clássicos que lemos, as estórias internas e criadoras de identidade numa disciplina - ou a prática etnográfica distinguem o nosso trabalho de tantos outros noutras áreas disciplinares, ou em ativismos vários, ou mesmo nas artes e humanidades. A minha terceira pesquisa, sobre a questão do casamento entre pessoas do mesmo sexo, com ancoramento etnográfico em Espanha, significou uma assunção do caráter interventivo da própria ciência social. Tal já vinha acontecendo com crónicas em jornais, intervenções televisivas, ativismo social e político e, por fim, o papel de deputado na Assembleia da República. Esta vertente de diluição das fronteiras entre ciência e participação cívica, ao mesmo tempo obrigando a um 
pensamento e ação em que se consiga manter algumas fronteiras de método e postura, creio sintetizar muito do que tenho dito até aqui, salvaguardando evidentemente tudo o que é específico num exemplo pessoal. Curiosamente e assim assumo também a influência que a minha geração sofreu dos debates pós-modernos, sobre a escrita etnográfica, o papel do conhecimento científico, etc. - o meu último livro (Almeida 2009) torna a ser sobre questões de sexualidade, tal como o primeiro texto publicado, acima referido.

Termino com o que não podia deixar de ser uma dúvida sobre qualquer noção de geração. Antes quis referir-me aos contextos - histórico, de economia política, de ar do tempo - que moldaram pessoas que, como eu, ainda tiveram um pé dentro da antropologia portuguesa anterior aos anos 80, do ressurgimento da disciplina, e que evoluíram com um pé "fora", em todos os sentidos da expressão. E que ficaram com a responsabilidade de construir - nas licenciaturas das diferentes universidades, nos centros de investigação, nas revistas, nas associações profissionais nacionais e internacionais, nas redes internacionais, no financiamento científico e na sociedade em geral com intervenções de todo o tipo - a antropologia que se faz em Portugal no século XXI.

\section{BIBLIOGRAFIA}

ALMEIDA, Miguel Vale de, 1989, "Não desejarás o teu próximo: a homossexualidade como pecado, crime e doença: espelho da construção social da sexualidade, do género e dos afectos", em F. O. Baptista et al. (orgs.), Estudos em Homenagem a Ernesto Veiga de Oliveira. Lisboa, JNICT, 851-860.

ALMEIDA, Miguel Vale de, 1995, Senhores de Si: Uma Interpretação Antropológica da Masculinidade. Lisboa, Fim de Século.

ALmeIDA, Miguel Vale de, 2009, A Chave do Armário: Homossexualidade, Casamento, Família. Lisboa, Imprensa de Ciências Sociais. 